\title{
Downregulation of miR-874-3p promotes chemotherapeutic resistance in colorectal cancer via inactivation of the Hippo signaling pathway
}

\author{
KAIQIAN QUE ${ }^{1}$, YUANHE TONG ${ }^{1}$, GANBO QUE ${ }^{2}$, LI LI $^{3}$, HONGCHENG LIN ${ }^{4}$, \\ SHUAI HUANG ${ }^{5}$, RUOYU WANG ${ }^{6}$ and LANGLANG TANG ${ }^{7}$
}

${ }^{1}$ Department of Radiation and Chemotherapy Oncology, The Affiliated Longyan First Hospital of Fujian Medical University;
${ }^{2}$ Department of Critical Care Medicine, The Second Hospital of Longyan, Longyan, Fujian; Departments of
${ }^{3}$ Pelvic Floor Center, ${ }^{4}$ Chinese Integrative Medicine Anorectal Surgery and ${ }^{5}$ Orthopaedic Surgery,
The Sixth Affiliated Hospital of Sun Yat-Sen University, Guangzhou 510655;
${ }^{6}$ Department of Oncology, The Affiliated Zhongshan Hospital of Dalian University, Dalian, Liaoning;
${ }^{7}$ Department of Radiology, The Affiliated Longyan First Hospital of Fujian Medical University,
Longyan, Fujian 364000, P.R. China

Received April 11, 2017; Accepted September 8, 2017

DOI: $10.3892 / o r .2017 .6041$

\begin{abstract}
Overcoming resistance to chemotherapy is an arduous challenge in the treatment of colorectal cancer (CRC), particularly since the underlying molecular mechanisms remain obscure. In the present study, we reported that miR-874-3p was markedly downregulated in CRC tissues compared with that in adjacent normal colorectal epithelial tissues. Upregulation of miR-874-3p attenuated the chemoresistance of CRC cells to 5-fluorouracil (5-FU) in vitro and in vivo. Conversely, inhibition of miR-874-3p yielded an opposite effect. Furthermore, our results demonstrated that miR-874-3p directly inhibited the expression of transcriptional co-activators YAP and TAZ of the Hippo signaling pathway, resulting in the inactivation of the TEAD transcription. Thus, our findings clarify a novel mechanism by which miR-874-3p restores chemotherapeutic sensitivity of CRC to 5-FU, indicating that offering miR874-3p mimics in combination with 5-FU may serve as a new therapeutic strategy to circumvent the chemoresistance in CRC.
\end{abstract}

\section{Introduction}

Colorectal cancer (CRC) is one of the most common malignancies and the third leading cause of cancer-related deaths

Correspondence to: Dr Langlang Tang, Department of Radiology, The Affiliated Longyan First Hospital of Fujian Medical University, 105 Jiuyi North Road, Longyan, Fujian 364000, P.R. China E-mail: tanglanglang99@163.com

Key words: miR-874-3p, chemotherapeutic resistance, colorectal cancer, Hippo signaling pathway worldwide (1,2). 5-Fluorouracil (5-FU)-based chemotherapy serves as the first-line chemotherapeutic drug of choice in the treatment of CRC. However, the response rate of CRC patients to 5 -FU remains no more than $15 \%$ in patients with advanced CRC (3). The combination treatments of 5-FU and oxaliplatin or irinotecan have markedly improved the prognosis of patients with CRC over the past few years, but the majority of patients still fail to respond to these combinational chemotherapeutic strategies $(4,5)$, which is primarily attributed to intrinsic or acquired resistance (6). These findings underscore the necessity to explore the underlying molecular mechanisms involved in the chemotherapeutic resistance of CRC, which may facilitate the development of effective therapeutic methods against chemotherapeutic resistance in CRC.

MicroRNAs (miRNAs) are short (19-22 nucleotide), non-coding RNAs that are known to regulate downstream target gene expression at a post-transcriptional level via interaction with specific sequences in the $3^{\prime}$ untranslated region (3'UTR) of downstream target genes, leading to mRNA degradation and/or translational inhibition (7). Physiologically, miRNAs play important roles in several biological and pathological processes, including proliferation, differentiation, apoptosis and cancer (8-11). Accumulating research evidence suggests that aberrant expression of miRNAs is implicated in the progression and metastasis of cancers via regulating varying biological functions, including proliferation, apoptosis, cancer stem cells and epithelial-mesenchymal transition (EMT) (10-13). Current research has supported that upregulation or downregulation of the expression of a certain miRNA can be directly tied to the response to chemotherapeutic agents (14). Emerging studies indicate that miRNAs are also identified as critical regulators in chemotherapeutic resistance in CRC. Ectopic expression of miR-451 has been reported to increase the sensitivity of CRC cells to irinotecan via targeting TP-binding cassette subfamily B member 1 (ABCB1) (15). 
Furthermore, Zhang et al revealed that miR-587 was elevated in CRC tissues and conferred the resistance of CRC cells to 5-FU via inhibiting PPP2R1B, an inhibitor of AKT signaling; importantly, inhibition of miR-587 resensitized CRC cells to 5-FU (16). These findings indicate that miRNAs play both a sensitizing and desensitizing role in chemotherapy in CRC.

Recent literature indicates that the targets and pathways involved in the molecular mechanisms of chemoresistance have been intensively studied (17). Cellular signaling pathways, including the Notch, Hippo, STAT3 and PI3K/Akt pathways, have been reported to be aberrantly activated or inactivated and play crucial roles in the chemotherapeutic resistance of CRC (18-20). For example, Notch-1 activation induced resistance to mitogen-activated protein kinase (MAPK) inhibitors in BRAF (V600E) melanoma cells and to tamoxifen in breast cancer cells, respectively. Importantly, applying a Notch-1 inhibitor reversed the drug resistance of melanoma and breast cancer cells to MAPK inhibitors and tamoxifen (18). The Hippo effector YAP was found to promote resistance to RAF- and MEK-targeted cancer therapies and cisplatin in oral squamous cell carcinoma and in tumors harboring BRAF V600E and RAS-mutaion $(21,22)$. Furthermore, accumulating evidence indicates that miRNAs play important roles in the resistance of different tumor cells to multiple anticancer drugs by modulating these signaling pathways (23-25). Thus, it is possible that combining conventional chemotherapeutic drugs with miRNAs would facilitate the development of novel therapeutic approaches to improve the efficacy of treatment.

In the present study, we found that miR-874-3p was significantly downregulated in CRC tissues compared with that in the adjacent normal tissues. Furthermore, upregulation of miR-874-3p increased the apoptosis ratio and decreased the mitochondrial potential of CRC cells treated with 5-FU in vitro and attenuated the chemoresistance of CRC cells to 5-FU in vivo. By contrast, silencing of miR-874-3p decreased the apoptosis ratio and increased the mitochondrial potential of CRC cells following 5-FU treatment in vitro and aggravated the chemoresistance of CRC cells to 5-FU treatment in vivo. Importantly, our results demonstrated that miR-874-3p directly inhibited YAP and TAZ, resulting in the inactivation of TEAD transcription and the downregulation of Hippo downstream target genes, including CTGF, BCL2L1 and cyclin A. Therefore, our findings revealed a novel mechanism for YAP/TAZ activation, which promotes the chemoresistance of CRC cells to 5-FU.

\section{Materials and methods}

Cell lines and cell culture. The human CRC cell lines HCT116 and SW480 were obtained from the American Type Culture Collection (ATCC; Manassas, VA, USA), and all human CRC cell lines were cultured according to the described ATCC protocol. The cell lines were maintained in RPMI-1640 medium (Invitrogen, Carlsbad, CA, USA) supplemented with $10 \%$ fetal bovine serum (FBS) (HyClone, Logan, UT, USA).

Patients and tumor tissues. A total of 20 paired CRC tissues with matched adjacent normal tissues from patients were obtained during surgery at the Sixth Affiliated Hospital of Sun Yat-Sen University (Guangzhou, China) between January 2010
Table I. Basic information concerning the 20 colorectal cancer patients for miR-874-3p expression analysis.

\begin{tabular}{lcc}
\hline & Cases (n) & Percentage (\%) \\
\hline Classification & 10 & 50 \\
Colon cancer & 10 & 50 \\
Rectal cancer & & \\
Sex & 15 & 75 \\
Male & 5 & 25 \\
Female & & \\
Age (years) & 9 & 45 \\
$<50$ & 11 & 55 \\
$\geq 50$ & & \\
Histologic subtype & 20 & 0 \\
Adenocarcinoma & 0 & 100 \\
Other & & 85 \\
Grade & 3 & \\
G1 & 17 & \\
G2-G3 & & \\
\hline
\end{tabular}

Table II. List of primers used in the reactions for real-time RT-PCR.

\begin{tabular}{ll} 
Gene & \multicolumn{1}{c}{ Sequence (5'-3') } \\
\hline CTGF-up & TGGAGATTTTGGGAGTACGG \\
CTGF-dn & CAGGCTAGAGAAGCAGAGCC \\
BCL2L1-up & CTGCTGCATTGTTCCCATAG \\
BCL2L1-dn & TTCAGTGACCTGACATCCCA \\
Cyclin A-up & GGAAGGCATTTTCTGATCCA \\
Cyclin A-dn & GCTAGGGCTGCTAACTGCAA
\end{tabular}

up, upregulated; dn, downregulated.

and December 2013 (Table I). Patients were diagnosed based on clinical and pathological evidence, and the specimens were immediately snap-frozen and stored in liquid nitrogen tanks. For the use of the clinical materials for research purposes, prior patient consent was obtained and approval from the Institutional Research Ethics Committee was procured.

RNA extraction, reverse transcription, and real-time PCR. Total RNA from tissues or cells was extracted using TRIzol (Life Technologies, Carlsbad, CA, USA) according to the manufacturer's instructions. Messenger RNA (mRNA) was polyadenylated using a poly(A) polymerase-based first-strand synthesis kit and reverse transcription (RT) of total mRNA was performed using a PrimeScript RT Reagent kit (both from Takara, Dalian, China) according to the manufacturer's protocol. miRNA was reverse transcribed of total mRNA using the RevertAid First Strand cDNA Synthesis kit (Thermo Fisher Scientific, Inc., Waltham, MA, USA) according to the manufacturer's protocol. Complementary DNA (cDNA) was 
Table III. List of primers used in the reactions for clone PCR.

Gene Sequence $\left(5^{\prime}-3^{\prime}\right)$

miR-874-up

miR-874-dn

YAP1-3'UTR-1609nt-up

YAP1-3'UTR-3464nt-dn

TAZ-3'UTR-43nt-up

TAZ-3'UTR-1936nt-dn
GAACTCCACTGTAGCAGAGATGGT

CATTTTTTCCACTCCTCTTCTCTC

AACAAAACGAGCATGAATTAACTCT

CAATTTATGTAAGTACCTAACATATGAGCAT

TCAGAGAAGTAAAAACCAGTACCAAA

CCAATGAAGTCCTCAACTGTTTAAT

up, upregulated; dn, downregulated.

amplified and quantified using the ABI 7500HT system using SYBR-Green I (both from Applied Biosystems, Foster City, CA, USA). Table II lists the primers used in the reactions. Real-time PCR was performed according to a standard method, as previously described (26). Primers for U6 and miR-874-3p were synthesized and purified by RiboBio (Guangzhou, China). U6 or glyceraldehyde-3-phosphate dehydrogenase (GAPDH) was used as an endogenous control for miRNA or mRNA, respectively. Relative fold of expression was calculated using the comparative threshold cycle $\left(2^{-\Delta \Delta \mathrm{Ct}}\right)$ method.

Plasmid, small interfering RNA and transfection. The miR-874-3p expression plasmid was generated by cloning the genomic pre-miR-874-3p gene into retroviral transfer plasmid pMSCV-puro (Clontech Laboratories, Inc., Tokyo, Japan) to generate plasmid pMSCV-miR-874-3p. pMSCV-miR-874-3p was co-transfected with the pIK packaging plasmid into 293FT cells using the standard calcium phosphate transfection method, as previously described (27). Thirty-six hours after the co-transfection, supernatants were collected and incubated with the cells to be infected for $24 \mathrm{~h}$ in the presence of Polybrene $(2.5 \mu \mathrm{g} / \mathrm{ml})$. After infection, puromycin $(1.5 \mu \mathrm{g} / \mathrm{ml})$ was used to select stably transduced cells over a 10 -day period. The luciferase reporter system of pTEAD-luc (\#83467; Addgene Inc., Cambridge, MA, USA) was used to examine the transcriptional activity of TEAD. The 3' untranslated regions (3'UTR) of human YAP and TAZ were PCR-amplified from genomic DNA and cloned into the pmirGLO luciferase reporter vector (Promega, Madison, WI, USA). The list of primers used in the clone reactions is presented in Table III. The miArrest plasmids for anti-miR-874-3p and negative control plasmids were constructed and cloned into phU6 plasmids by GeneChem (Shanghai, China). The sequence of anti-miR-874-3p was TCGGTCCCTCGGGCCAGGGCAG. Small interfering RNA (siRNA) for YAP and TAZ knockdown (50 nmol/l) were obtained from RiboBio. Transfection of siRNAs and plasmids was performed using Lipofectamine 3000 (Life Technologies) according to the manufacturer's instructions.

Western blot analysis. Nuclear/cytoplasmic fractionation was separated using Cell Fractionation kit according to the manufacturer's instructions, and the whole cell lysates were extracted using RIPA buffer (both from Cell Signaling Technology, Beverly, MA, USA). Western blotting was performed according to a standard method, as previously described (28). Antibodies against YAP, TAZ, Bcl-2 and Bcl-xL were purchased from Abcam (Cambridge, MA, USA). The membranes were stripped and reprobed with an anti- $\alpha$-tubulin antibody (Sigma-Aldrich, St. Louis, MO, USA) as the loading control.

Flow cytometric analysis. Flow cytometric analysis of apoptosis was carried out using the FITC Annexin V Apoptosis Detection Kit I (BD Biosciences, Bedford, MA, USA), and was performed and presented according to the described protocol. Briefly, cells were dissociated with trypsin and resuspended at $1 \times 10^{6}$ cells $/ \mathrm{ml}$ in binding buffer with $50 \mu \mathrm{l} / \mathrm{ml} \mathrm{FITC}$ Annexin $\mathrm{V}$ and $50 \mu \mathrm{l} / \mathrm{ml}$ propidium iodide (PI). The cells were subsequently incubated for $15 \mathrm{~min}$ at room temperature, and then were analyzed using a Gallios flow cytometer (Beckman Coulter, Inc. Brea, CA, USA). The cell inner mitochondrial membrane potential $(\Delta \psi \mathrm{m})$ was detected by flow cytometry using MitoScreen JC-1 staining kit (BD Biosciences), and was carried out and presented according to the described protocol. Briefly, cells were dissociated with trypsin and resuspended at $1 \times 10^{6}$ cells $/ \mathrm{ml}$ in assay buffer, and then incubated at $37^{\circ} \mathrm{C}$ for $15 \mathrm{~min}$ with $10 \mu \mathrm{l} / \mathrm{ml} \mathrm{JC}-1$. Before being analyzed by flow cytometry, the cells were washed twice using assay buffer. Flow cytometric data were analyzed using FlowJo 7.6 software (TreeStar, Inc., Ashland, OR, USA).

Caspase- 9 or -3 activity assays. Activity of caspase- 9 or -3 was analysis by spectrophotometry using caspase-9 colorimetric assay kit or caspase-3 colorimetric assay kit (KeyGen, Nanjing, China), and was carried out and presented according to the described protocol. Briefly, $5 \times 10^{6}$ cells or $100 \mathrm{mg}$ fresh tumor tissues were washed with cold phosphate-buffered saline (PBS) and resuspended in lysis buffer and incubated on ice for $30 \mathrm{~min}$. Then, $50 \mu \mathrm{l}$ of the cell suspension, $50 \mu \mathrm{l}$ of reaction buffer, and $5 \mu \mathrm{l}$ of caspase-3/-9 substrate were mixed, and then incubated at $37^{\circ} \mathrm{C}$ for $4 \mathrm{~h}$. The absorbance was measured at $405 \mathrm{~nm}$, and BCA protein quantitative analysis was used as the reference to normal each experiment groups.

Tumor xenografts. Four-week-old BALB/c-nu female mice weighing 15-20 g were maintained in a standard pathogenfree environment where the animals were housed in sterile cages under laminar flow hoods in a $20-26^{\circ} \mathrm{C}$ temperature controlled room with a 12 -h light/12-h dark cycle and fed 
A TCGA (COAD \& READ)

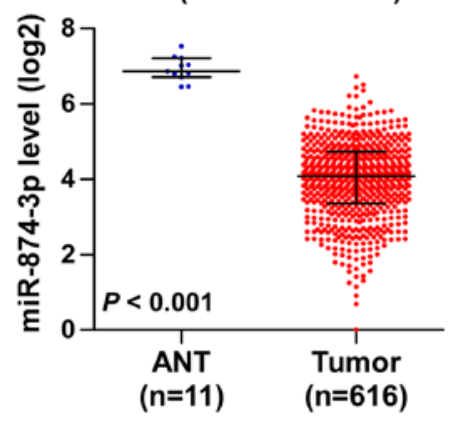

B TCGA (COAD \& READ)

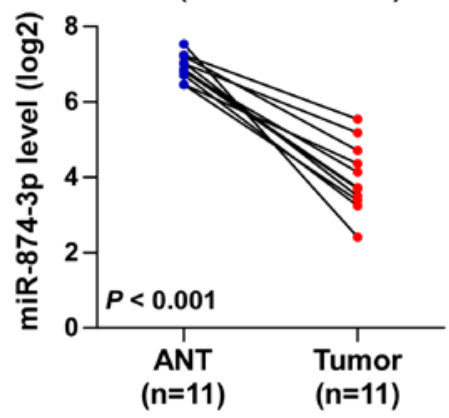

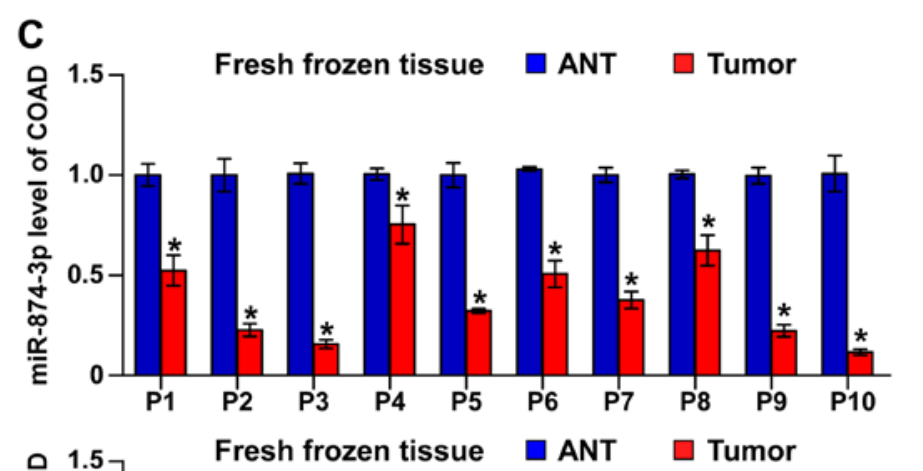

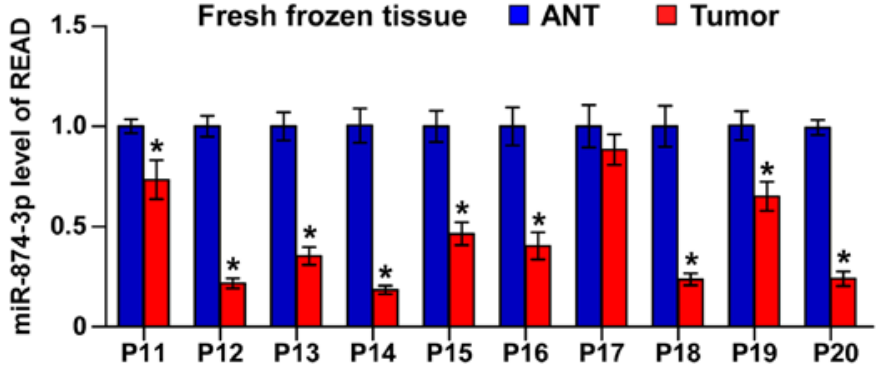

Figure 1. miR-874-3p is downregulated in CRC tissues. (A) miR-874-3p expression level was decreased in CRS tissues compared with the adjacent normal tissues as assessed by analyzing the TCGA colorectal cancer miRNA sequencing dataset (adjacent normal tissue, $\mathrm{n}=11 ; \mathrm{colorectal}$ cancer, $\mathrm{n}=616$ ). Lines represent median and lower/upper quartiles; $\mathrm{P}<0.001$. (B) miR-874-3p expression level was reduced in 11 colorectal cancer tissues compared with the matched adjacent normal tissues; $\mathrm{P}<0.001$. (C) Real-time PCR analysis of miR-874-3p expression in 10 paired freshly collected colon cancer tissues and 10 rectal cancer tissues. Transcript levels were normalized to U6 expression; ${ }^{*} \mathrm{P}<0.05$.

autoclaved chow and water. All experimental procedures were approved by the Institutional Animal Care and Use Committee (IACUC) of Guangdong Medical College. The 4-6 week-old BALB/c-nu mice were randomly divided into four groups $\left(n=5 /\right.$ group) and the indicated cells $\left(2 \times 10^{6}\right)$ were subcutaneously inoculated into the inguinal folds of the nude mice. Ten days following cell inoculation, the mice were intraperitoneally injected (50 mg/kg/day) with 5 -FU for 4 weeks (29). For the experimental testing to ascertain whether miR-874-3p mimics enhance the sensitivity of CRC cells to 5-FU, animals were injected with $100 \mu \mathrm{lmiR}-874-3 \mathrm{p}(1 \mathrm{mmol} / \mathrm{l})$ or negative control through the lateral tail vein every 4 days for 4 weeks. Tumor volume was determined using an external caliper and calculated using the equation $\left(\mathrm{L} \mathrm{x} \mathrm{W}^{2}\right) / 2$. On day 38, tumors were imaged using an IVIS imaging system (Caliper, Alameda, CA, USA). Annimals were euthanized, tumors were excised, weighed and stored in liquid nitrogen tanks.

Luciferase assay. Cells $\left(4 \times 10^{4}\right)$ were seeded in triplicate in 24-well plates and cultured for $24 \mathrm{~h}$. Cells were transfected with $100 \mathrm{ng}$ HOP-flash reporter luciferase plasmid, HIP-flash (HOP-flash mutant), pmirGLO-YAP1-3'UTR or -TAZ-3'UTR, luciferase plasmid, plus $5 \mathrm{ng}$ pRL-TK Renilla plasmid (Promega) using Lipofectamine 3000 (Invitrogen) according to the manufacturer's recommendation. Luciferase and Renilla signals were measured $36 \mathrm{~h}$ after transfection using a Dual-Luciferase Reporter Assay kit (Promega) according to the manufacturer's protocol.

miRNA immunoprecipitation. Cells were co-transfected with HA-Ago2, followed by HA-Ago2 immunoprecipitation using HA-antibody. Real-time PCR analysis of the IP material was used to test the association of the mRNA of YAP1 and TAZ with the RISC complex. The specific processes were performed as previously described (30).

Statistical analysis. All values are presented as means \pm standard deviation (SD). Significant differences were determined using GraphPad 5.0 software (GraphPad Software, Inc., La Jolla, CA, USA). One-way ANOVA was used to determine statistical differences between multiple testing. Student's t-test was used to determine statistical differences between two groups. $\mathrm{P}<0.05$ was considered significant. All the experiments were repeated three times. 
A

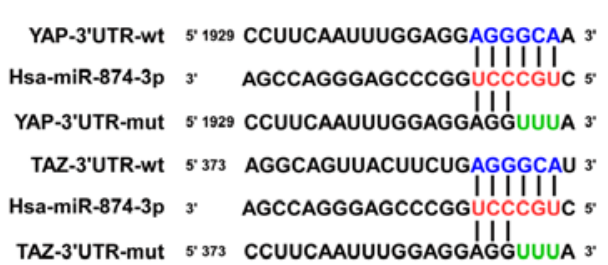

D

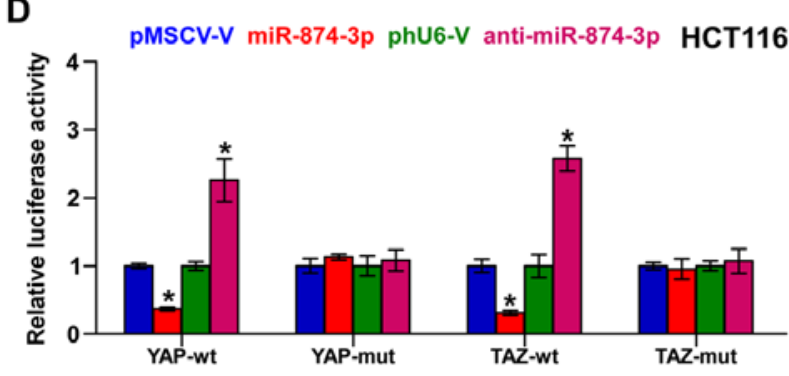

$\mathbf{F}$

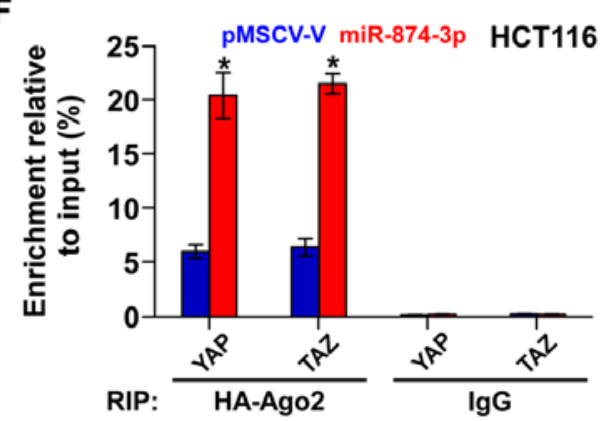

B

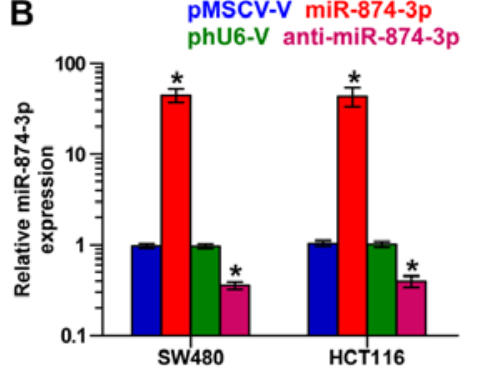

C

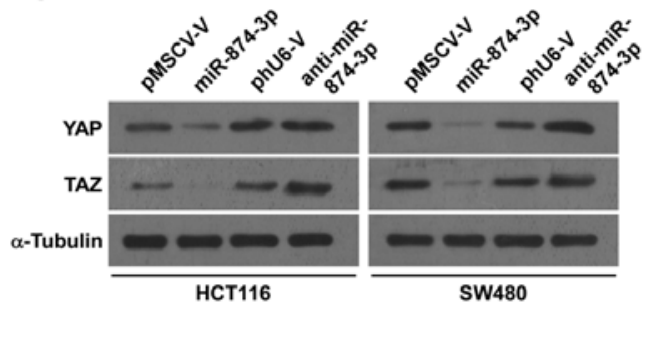

E
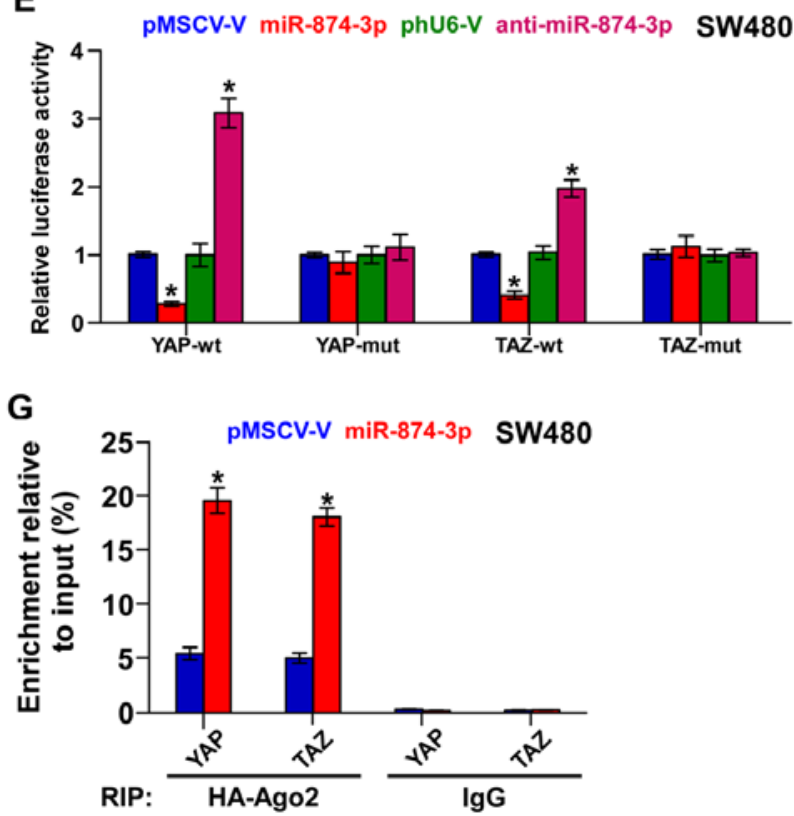

Figure 2. miR-874-3p targets YAP and TAZ. (A) Predicted miR-874-3p target sequence in 3'UTRs of YAP and TAZ. (B) Real-time PCR analysis of miR874-3p expression in the indicated CRC cells. Transcript levels were normalized by U6 expression. Each column shows the mean \pm SD of three independent experiments; "P<0.05. (C) Western blotting of YAP and TAZ expression in the indicated cells. $\alpha$-tubulin served as the loading control. (D and E) Luciferase assay of the cells transfected with pmirGLO-3'UTR reporter in miR-874-3p overexpressing or silenced cells. Each column shows the mean \pm SD of three independent experiments; ${ }^{\circ} \mathrm{P}<0.05$. ( $\mathrm{F}$ and $\mathrm{G}$ ) miRNP IP assay showing the association between miR-874-3p and YAP and TAZ transcripts in CRC cells. Pull-down of IgG antibody served as the negative control. Each column shows the mean \pm SD of three independent experiments; ${ }^{*} \mathrm{P}<0.05$.

\section{Results}

miR-874-3p is downregulated in CRC tissues. By analyzing The Cancer Genome Atlas (TCGA) CRC miRNA sequencing datasets, we found that miR-874-3p expression was downregulated in CRC tissues compared with that in adjacent normal colorectal tissues, as well as in the 11 paired primary CRC tissue samples compared with their matched adjacent normal tissue samples (Fig. 1A and B). We further confirmed miR-874-3p expression in our own 20 paired CRC tissues. Consistent with TCGA analysis, we found that the expression level of miR-874-3p was significantly differentially downregulated in 19/20 primary CRC tissue samples compared with their matched adjacent normal tissue samples (Fig. 1C). Thus, these results indicate that downregulation of miR-874-3p may be involved in the progression of CRC.

miR-874-3p targets YAP and TAZ in CRC cells. The transcriptional co-activators YAP and TAZ are major components of the Hippo signaling pathway and play a critical role in the development and progression of multiple cancer types, including CRC (31-33). Using the publicly available algorithms TargetScan and miRanda, we found that transcriptional factors of Hippo signaling, including TAP and TAZ, may be potential targets of miR-874-3p (Fig. 2A). We further constructed stably expressing miR-874-3p CRC cells via exogenously overexpressing miR-874-3p or endogeneously silencing miR-874-3p via virus transduction (Fig. 2B). Western blot analysis revealed that miR-874-3p overexpression reduced the expression levels of TAP and TAZ. In contrast, silencing of miR-874-3p increased the expression of TAP and TAZ, suggesting that miR-874-3p negatively regulated these proteins in CRC cells (Fig. 2C). Furthermore, luciferase assay showed that miR-874-3p overexpression attenuated, while silencing of miR-874-3p elevated the reporter activity driven by the 3'UTRs of TAP and TAZ transcripts, but not by the mutant 3'UTRs of these transcripts within miR-874-3p-binding seed regions in HCT116 and SW480 cells (Fig. 2D and E). Moreover, microribonucleoprotein (miRNP) immunoprecipitation (IP) assay revealed an association of miR-874-3p with TAP and TAZ transcripts (Fig. 2F and G), further indicating the direct repressive effects of miR-874-3p on TAP and TAZ. Collectively, our 

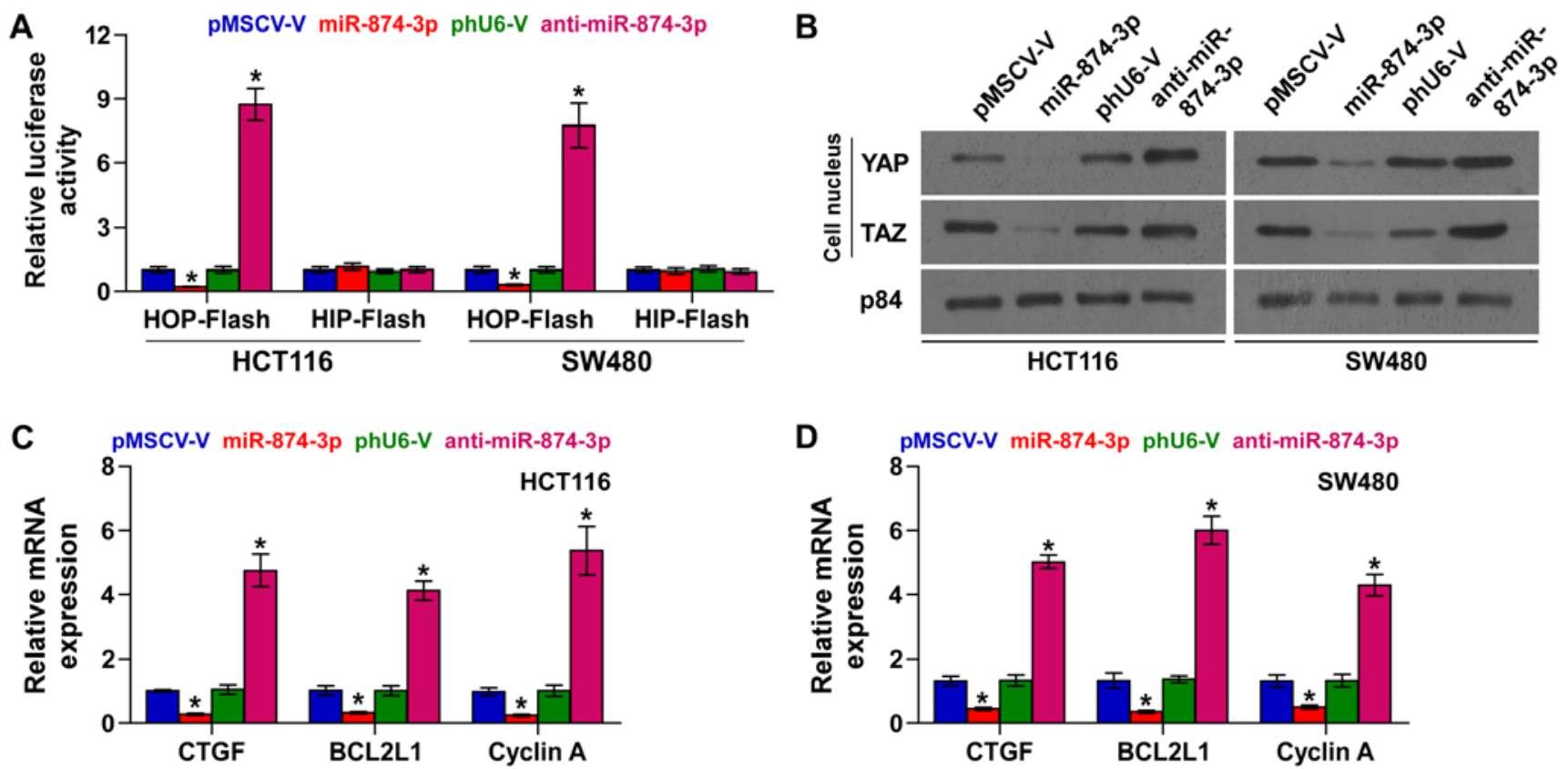

Figure 3. Downregulation of miR-874-3p inactivates the Hippo signaling pathway. (A) TEAD transcriptional activity was assessed by luciferase reporter constructs in the indicated cells. Each column shows the mean \pm SD of three independent experiments; $\mathrm{P}<0.05$. (B) Western blotting of nuclear YAP and TAZ expression in the indicated cells. The nuclear protein p84 was used as the nuclear protein marker. (C and D) Real-time PCR analysis of CTGF, BCL2L1 and cyclin $\mathrm{A}$ in the indicated cells. Each column shows the mean $\pm \mathrm{SD}$ of three independent experiments; ${ }^{*} \mathrm{P}<0.05$.

results suggest that miR-874-3p directly targets TAP and TAZ, leading to activation of Hippo signaling.

Downregulation of miR-874-3p inactivates the Hippo signaling pathway. YAP and TAZ inactivate the Hippo signaling pathway through nuclear translocation and interaction with TEAD transcription factors $(34,35)$. Thus, we further examined the effects of miR-874-3p on Hippo signaling activity. As shown in Fig. 3A, we found that miR-874-3p overexpression significantly decreased, while silencing of miR-874-3p enhanced TEAD-dependent luciferase activity. Moreover, cellular fractionation and western blot analysis revealed that overexpression of miR-874-3p decreased nuclear accumulation of YAP and TAZ, while silencing of miR-874-3p increased their nuclear expression (Fig. 3B). Real-time PCR analysis revealed that miR-874-3p overexpression significantly decreased, while silencing of miR-874-3p increased expression levels of multiple downstream genes including CTGF, BCL2L1 and cyclin A in the CRC cells (Fig. 3C and D). Thus, these results demonstrated that downregulation of miR-874-3p inactivates the Hippo signaling pathway in CRC cells.

Upregulation of miR-874-3p restores chemosensitivity in $C R C$ cells in vitro. The role of miR-874-3p in the chemoresistance of CRC cells was further investigated following treatment of cells with first-line anti-CRC drug 5-FU $(10 \mu \mathrm{M}, 24 \mathrm{~h})$ in vitro (36). As shown in Fig. 4A, we found that miR-874-3p overexpression increased, while silencing of miR-874-3p decreased the apoptosis rate of HCT116 and SW480 cells treated by 5-FU. In addition, miR-874-3p overexpression decreased, while silencing of miR-874-3p increased the mitochondrial potential of HCT116 and SW480 cells under treatment of 5-FU (Fig. 4B). Moreover, we further examined the effect of miR-874-3p on the expression levels of the anti-apoptotic proteins Bcl-2 and Bcl-xL, and the activity of caspase- 9 and -3 . We found that overexpression of miR-874-3p decreased Bcl-2 and Bcl-xL expression, but enhanced the activity of caspase- 9 and -3 . Conversely, silencing of miR-874-3p exhibited an opposite effect (Fig. 4C-E). Therefore, these results demonstrated that upregulation of miR-874-3p restores the sensitivity of CRC cells to 5-FU in vitro.

Upregulation of miR-874-3p sensitizes CRC cells to 5-FU in vivo. We further examined the effect of miR-874-3p on the chemoresistance of CRC cells in vivo. Mice were randomly divided into four groups ( $\mathrm{n}=5 /$ group) and subcutaneously inoculated ( $3 \times 10^{6}$ HCT116 cells/mouse) in the left dorsal flank. Two weeks later, each group of mice was intratumorally injected with $150 \mu \mathrm{g}$ mimic control, miR-874-3p, anti-miR-874-3p control or the miR-874-3p inhibitor $(2 \mathrm{mg} / \mathrm{ml})$ three times each week for 4 weeks, combined with intraperitoneal injection of $5-\mathrm{FU}$ (50 mg/kg/day) (Fig. 5A). As shown in Fig. 5B and C, the tumor volumes and weight were decreased in the miR874-3p-overexpressing plus 5-FU group, but were markedly increased in the anti-miR-874-3p plus 5-FU group, compared to the respective controls. These findings indicate that upregulation of miR-874-3p sensitizes CRC cells to 5-FU in vivo.

YAP and TZA are essential for miR-874-3p downregulated-induced chemoresistance. We then explored the functional significance of YAP and TAZ in the chemoresistance of CRC cells. As shown in Fig. 6A and B, individual inhibition of YAP or TAZ in the miR-874-3p-silenced cells abrogated the effects of miR-874-3p downregulation on the apoptotic ratio and mitochondrial potential. Furthermore, the inhibitory effects of miR-874-3p downregulation on caspase-3 and -9 
A

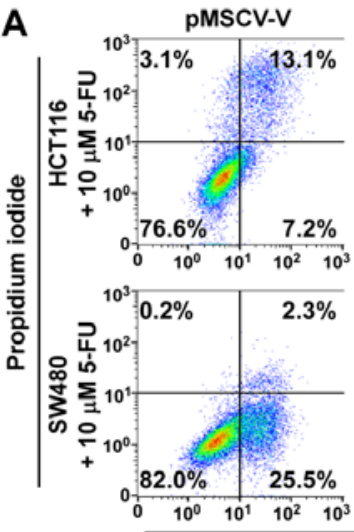

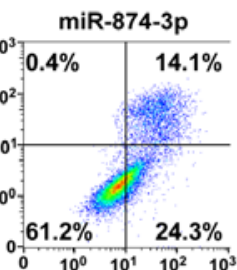
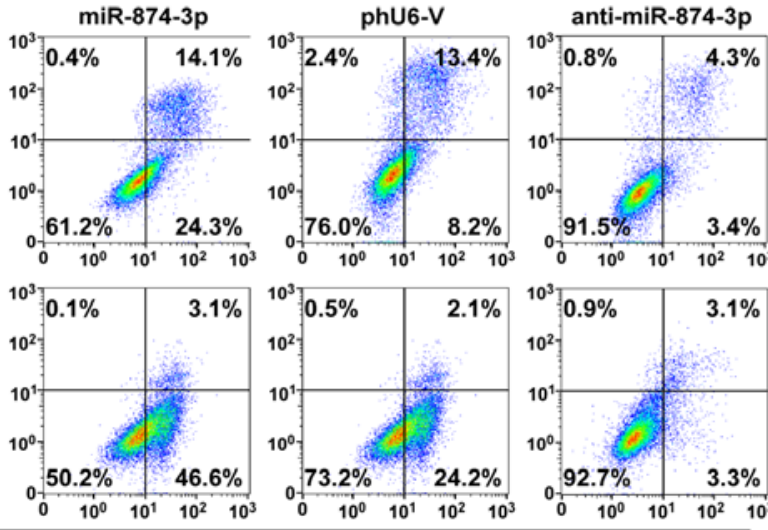

Annexin V-FITC

B
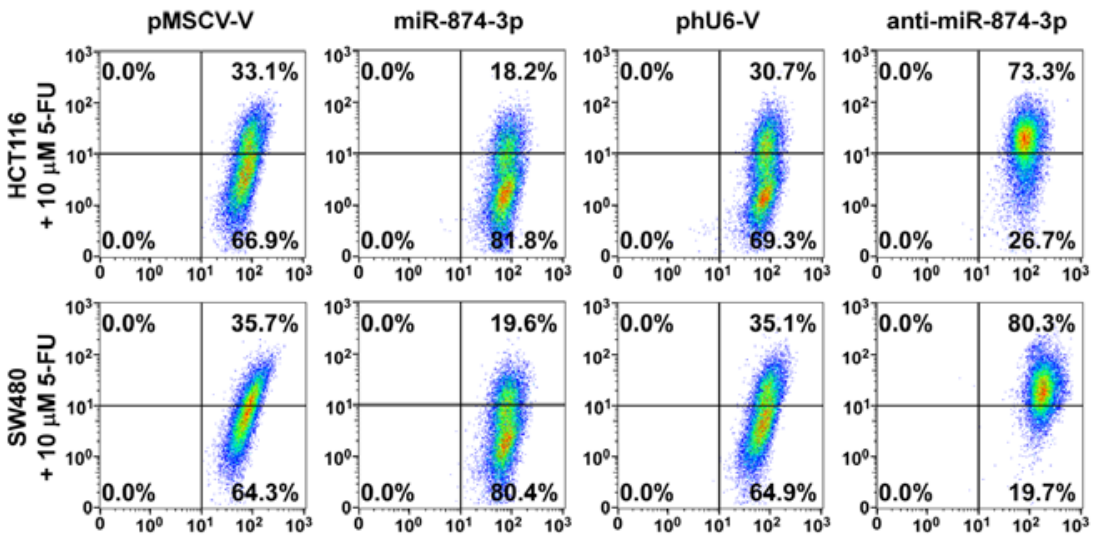

$\overline{\grave{u}}$
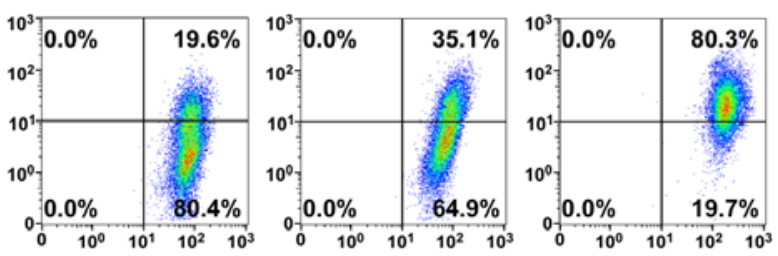

JC-1 Green

C

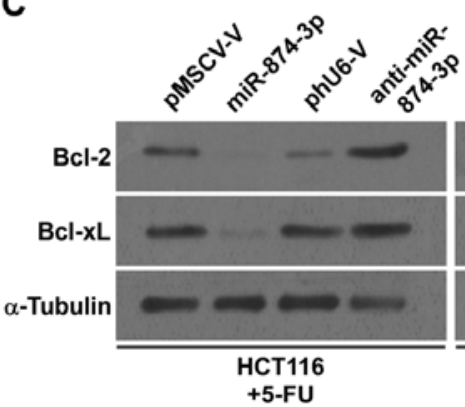

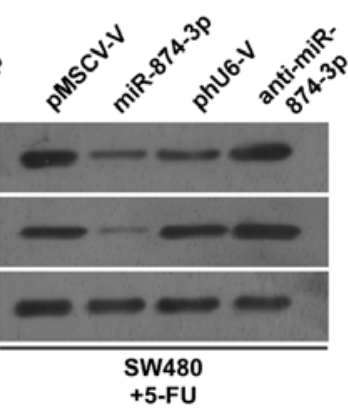

D

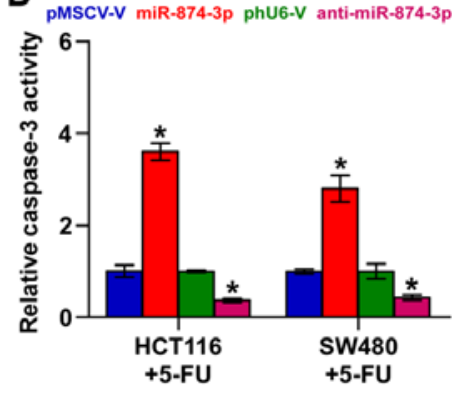

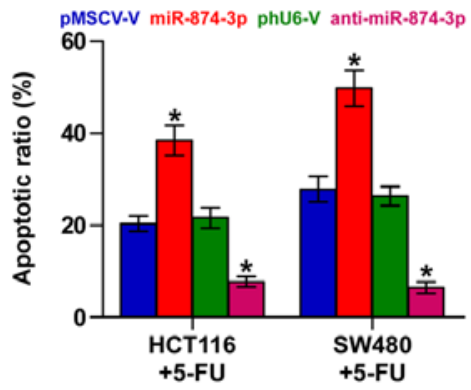

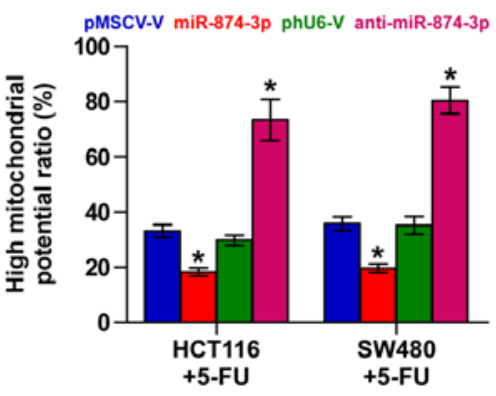

Figure 4. Downregulation of miR-874-3p promotes chemoresistance in CRC cells in vitro. (A) Annexin V-FITC/PI staining of the indicated cells treated with 5-FU $(10 \mu \mathrm{M})$ for $36 \mathrm{~h}$. Each column shows the mean \pm SD of three independent experiments; ${ }^{*} \mathrm{P}<0.05$. (B) The JC-1 staining showed that upregulation of miR-874-3p decreased, while silencing of miR-874-3p increased the mitochondrial potential in the indicated CRC cells. Each column shows the mean \pm SD of three independent experiments; ${ }^{*} \mathrm{P}<0.05$. (C) Western blot analysis of Bcl-2 and Bcl-xL in the indicated cells. (D and E) Analysis of the activities of (D) caspase- 3 and (E) caspase -9 was detected by the cleaved forms of these two proteins. Each column shows the mean \pm SD of three independent experiments; ${ }^{*} \mathrm{P}<0.05$.
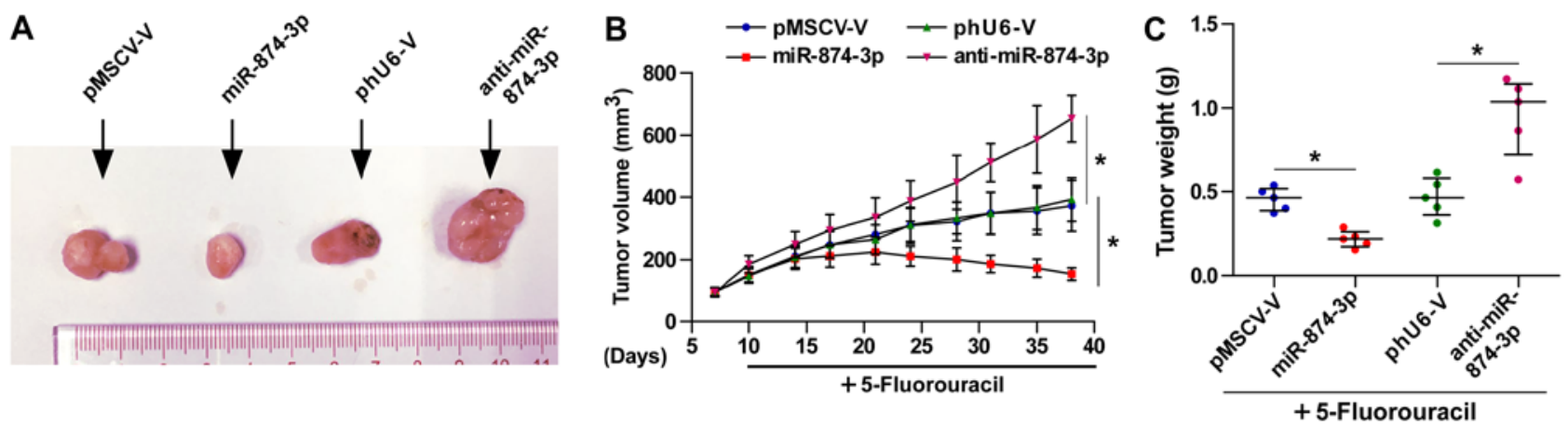

Figure 5. Upregulation of miR-874-3p restores the sensitivity of CRC cells to 5-FU in vivo. (A) Representative images of the tumors in the xenograft model of nude mice. (B) Ten days following the inoculation of HCT116 cells, mice were intraperitoneally injected with $50 \mathrm{mg} / \mathrm{kg} 5$-FU/day for 4 weeks. Tumor volume in the indicated groups was measured from the fifth day at 5 -day intervals. Data are presented as the mean \pm SD. (C) Tumor weights of each group; ${ }^{*}<0.05$. 

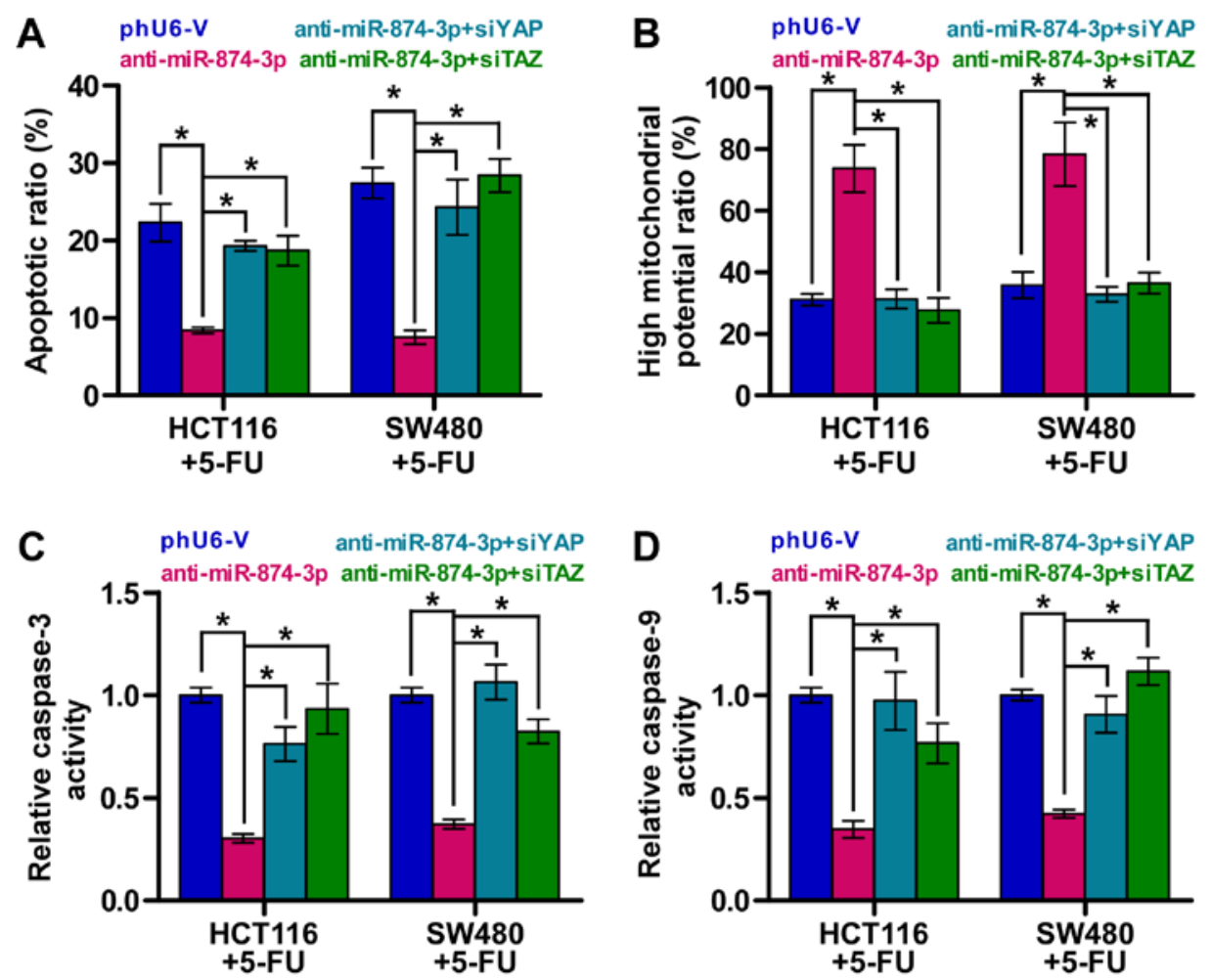

Figure 6. YAP and TZA are essential for miR-874-3p downregulation-induced chemoresistance. (A) Individual silencing of YAP and TAZ rescued the apoptotic rate of CRC cells decreased by silencing of miR-874-3p. Each column shows the mean \pm SD of three independent experiments; ${ }^{*} \mathrm{P}<0.05$. (B) Individual silencing of YAP and TAZ reversed the mitochondrial potential of CRC cells increased by silencing of miR-874-3p. Each column shows the mean \pm SD of three independent experiments; $\mathrm{P}<0.05$. (C and D) Individual silencing of YAP and TAZ attenuated the caspase- 3 or caspase-9 activity in CRC cells decreased by anti-miR-874-3p. Each column shows the mean \pm SD of three independent experiments; ${ }^{P}<0.05$.

were attenuated by separate silencing of YAP and TAZ in CRC cells (Fig. 6C and D). Taken together, our results indicate that YAP and TAZ are functionally relevant effects of miR-874-3p in the chemotherapeutic response of CRC cells.

\section{Discussion}

In the present study, our results showed that miR-874-3p was downregulated in colorectal cancer (CRC) tissues compared with that in the adjacent normal tissues. Furthermore, upregulation of miR-874-3p suppressed, while silencing of miR-874-3p enhanced the chemoresistance of CRC cells to 5-FU in vitro and in vivo. Our results further indicated that miR-874-3p directly inhibited the expression of YAP and TAZ, leading to the inactivation of TEAD transcription and the downregulation of Hippo downstream target genes, including CTGF, BCL2L1 and cyclin A. Therefore, our findings reveal a novel mechanism of miR-874-3p in restoring the chemotherapeutic sensitivity of CRC cells to 5-FU.

The Hippo pathway, which exerts its function as a novel tumor suppressor pathway, is an essential regulator of several biological processes, including cell proliferation, apoptosis, stem cell maintenance and tumorigenesis (37-41). The mammalian Hippo pathway is mainly composed of four core kinase cascade components: STE20-like protein kinase 1/2 (MST1/2), large tumor suppressor 1/2 (LATS1/2), Salvador homologue 1 (SAV1) and MOB kinase activator 1 (MOB1) $(41,42)$. Physiologically, when Hippo signaling is active, Yes-associated protein (YAP) and transcriptional co-activator with PDZ-binding motif (TAZ) are phosphorylated and restricted in the cytoplasm by core complexes formed from, MST1/2, LATS1/2, SAV1 and MOB1 (40). Conversely, inactivation of the Hippo pathway leads to nuclear translocation of TAZ/YAP, which interact with TEA/ATTS domain (TEAD) transcription factors and transactivate downstream target genes $(43,44)$. YAP and TAZ are important downstream effectors of the Hippo pathway and play crucial roles in various cellular processes $(45,46)$. Accumulating studies indicate that aberrant activation of YAP and TAZ has been implicated in the pathogenesis of several cancers, including CRC, liver and lung cancer (47-49). The activity or expression of YAP/TAZ are regulated by a number of factors, such as mitogenic growth factors, EGFR and leukemia inhibitory factor receptor (50-52). Furthermore, microRNAs have been reported to regulate the Hippo signaling pathway by posttranscriptional suppression of multiple target mRNAs of Hippo signaling components $(53,54)$. For example, in ovarian cancer, miR-129-5p inhibited proliferation and survival via directly repressing transcriptional co-activators YAP and TAZ of Hippo signaling (31). In addition, Chen et al reported that miR-181c was elevated in chemoresistant pancreatic cancer tissues compared with that in chemosensitive pancreatic cancer tissues. Upregulation of miR-181c promoted chemoresistance via targeting multiple core components of Hippo signaling, including MST1, LATS2, MOB1 and SAV1, leading to inactivation of the Hippo signaling pathway (55). These studies indicate that miRNAs play important roles in regulating the activity of the Hippo pathway, which is further 
involved in the development and progression of cancer via varying biological function. In the present study, through bioinformatic analysis, we found that YAP and TAZ are theoretical targets of miR-874-3p. Our results further revealed that upregulation of miR-874-3p decreased, while silencing of miR-874-3p increased expression and nuclear translocation of TAP and TAZ and expression levels of multiple downstream genes of the Hippo signaling pathway. Furthermore, overexpression of miR-874-3p attenuated, while silencing of miR-874-3p enhanced the chemoresistance of CRC cells to 5 -FU in vitro and in vivo. Importantly, our findings demonstrated that YAP and TZA mediated the stimulatory roles for miR-874-3p downregulation in chemoresistance in CRC cells. Collectively, our results indicate that downregulation of miR874-3p inactivates the Hippo signaling pathway via targeting YAP and TAZ in CRC cells, which promotes chemoresistance of CRC cells to 5-FU.

A number of studies have indicated that dysregulation of miRNAs promotes chemoresistance in various types of cancer and may be potential targets for the treatment of cancer $(56,57)$. Research has also demonstrated the implications of miRNAs in chemotherapeutic resistance in CRC. Enforced expression of miR-204-5p was found to restore chemotherapeutic sensitivity of CRC cells via downregulating RAB22A (58). Furthermore, Fang et al reported that miR17-5p contributes to chemotherapeutic resistance by repressing PTEN expression (59). Herein, we found that miR-874-3p was downregulated in CRC tissues compared with that in adjacent normal tissues. We further demonstrated that miR-874-3p targets YAP1 and TAZ and downregulation of miR-874-3p promotes chemotherapeutic resistance of CRC cells to 5-FU by inactivating the Hippo signaling pathway. Inactivation of the Hippo signaling pathway has been demonstrated to be involved in the chemoresistance in cancers (60). Fujimoto et al reported that protease-activated receptor 1 (PAR1) promoted multidrug resistance by inhibiting the Hippo signaling pathway in gastric cancer (61). These results indicated that the Hippo signaling pathway plays an important role in the development of chemotherapeutic resistance. More importantly, our findings indicated that the application of miR-874-3p mimics significantly sensitized CRC cells to 5-FU treatment in vitro and in vivo, supporting an effective role of miR-874-3p in the chemotherapy of CRC. Taken together, our results propose that miR-874-3p combined with 5-FU may be used as a potential therapeutic strategy against the chemoresistance of CRC.

Dysregulation of miR-874-3p has been reported to be implicated in several disorders, including intestinal barrier dysfunction, skeletal anabolism, allergic rhinitis, asthma, myogenesis and cognitive impairment (62-68), as well as in the progression and metastasis of several malignancies, such as osteosarcoma, breast, gastric and lung cancer, and head and neck squamous cell carcinoma (69-76). Furthermore, emerging evidence indicates that miR-874-3p is downregulated in CRC and upregulation of miR-874-3p inhibits growth, induces apoptosis and reverses chemoresistance in CRC (77-79). However, the correlation between miR-874-3p expression and chemotherapeutic response in CRC clinical tissues and the specific mechanism for the chemotherapeutic response are poorly known. Consistently, we found that miR-874-3p was markedly downregulated in tumor tissues compared with that in the normal tissues. Furthermore, ectopic expression of miR874-3p increased the apoptosis induced by $5-\mathrm{FU}$ by decreasing mitochondrial potential, decreasing expression of anti-apoptotic proteins Bcl-2 and Bcl-xL and increasing the activity of caspase-9 and caspase-3 via targeting downstream effectors YAP1 and TAZ of the Hippo signaling pathway. Conversely, inhibition of miR-874-3p played an opposite effect. Therefore, our results demonstrated that downregulation of miR-874-3p promoted chemoresistance of CRC cells to 5-FU via inactivating the Hippo signaling pathway.

In summary, our findings revealed that downregulation of miR-874-3p contributes to the chemoresistance of CRC cells to 5-FU via targeting YAP and TAZ, resulting in inactivation of the Hippo signaling pathway. Thus, improved understanding of the precise role of miR-874-3p in the chemoresistance of CRC and activation of the Hippo signaling pathway promises to increase our knowledge of the biological basis of chemoresistance development, which may facilitate the development of new therapeutic strategies against CRC.

\section{Acknowledgements}

The present study was supported by grants from the National Natural Science Foundation of China (no. 81402227), and the Guangdong Natural Science Foundation (no. 2014A030310157).

\section{References}

1. Jemal A, Siegel R, Ward E, Hao Y, Xu J and Thun MJ: Cancer statistics, 2009. CA Cancer J Clin 59: 225-249, 2009.

2. Ricci-Vitiani L, Fabrizi E, Palio E and De Maria R: Colon cancer stem cells. J Mol Med 87: 1097-1104, 2009.

3. Johnston PG and Kaye S: Capecitabine: A novel agent for the treatment of solid tumors. Anticancer Drugs 12: 639-646, 2001.

4. Giacchetti S, Perpoint B, Zidani R, Le Bail N, Faggiuolo R, Focan C, Chollet P, Llory JF, Letourneau Y, Coudert B, et al: Phase III multicenter randomized trial of oxaliplatin added to chronomodulated fluorouracil-leucovorin as first-line treatment of metastatic colorectal cancer. J Clin Oncol 18: 136-147, 2000.

5. Douillard JY, Cunningham D, Roth AD, Navarro M, James RD, Karasek P, Jandik P, Iveson T, Carmichael J, Alakl M, et al: Irinotecan combined with fluorouracil compared with fluorouracil alone as first-line treatment for metastatic colorectal cancer: A multicentre randomised trial. Lancet 355: 1041-1047, 2000.

6. Longley DB and Johnston PG: Molecular mechanisms of drug resistance. J Pathol 205: 275-292, 2005.

7. Bartel DP: MicroRNAs: Target recognition and regulatory functions. Cell 136: 215-233, 2009.

8. Bartel DP: MicroRNAs: Genomics, biogenesis, mechanism, and function. Cell 116: 281-297, 2004.

9. Calin GA and Croce CM: MicroRNA signatures in human cancers. Nat Rev Cancer 6: 857-866, 2006.

10. Ren D, Wang M, Guo W, Huang S, Wang Z, Zhao X, Du H, Song L and Peng X: Double-negative feedback loop between ZEB2 and miR-145 regulates epithelial-mesenchymal transition and stem cell properties in prostate cancer cells. Cell Tissue Res 358: 763-778, 2014.

11. Ren D, Wang M, Guo W, Zhao X, Tu X, Huang S, Zou X and Peng X: Wild-type p53 suppresses the epithelial-mesenchymal transition and stemness in PC-3 prostate cancer cells by modulating miR-145. Int J Oncol 42: 1473-1481, 2013.

12. Guo W, Ren D, Chen X, Tu X, Huang S, Wang M, Song L, Zou X and Peng X: HEF1 promotes epithelial mesenchymal transition and bone invasion in prostate cancer under the regulation of microRNA-145. J Cell Biochem 114: 1606-1615, 2013.

13. Zhang X, Liu J, Zang D, Wu S, Liu A, Zhu J, Wu G, Li J and Jiang L: Upregulation of miR-572 transcriptionally suppresses SOCS1 and p21 and contributes to human ovarian cancer progression. Oncotarget 6: 15180-15193, 2015. 
14. Chen X, Ba Y, Ma L, Cai X, Yin Y, Wang K, Guo J, Zhang Y, Chen J, Guo X, et al: Characterization of microRNAs in serum: A novel class of biomarkers for diagnosis of cancer and other diseases. Cell Res 18: 997-1006, 2008.

15. Bitarte N, Bandres E, Boni V, Zarate R, Rodriguez J, GonzalezHuarriz M, Lopez I, Javier Sola J, Alonso MM, Fortes P, et al: MicroRNA-451 is involved in the self-renewal, tumorigenicity, and chemoresistance of colorectal cancer stem cells. Stem Cells 29: 1661-1671, 2011 .

16. Zhang Y, Talmon G and Wang J: MicroRNA-587 antagonizes 5-FU-induced apoptosis and confers drug resistance by regulating PPP2R1B expression in colorectal cancer. Cell Death Dis 6: e1845, 2015.

17. Szakács G, Paterson JK, Ludwig JA, Booth-Genthe C and Gottesman MM: Targeting multidrug resistance in cancer. Nat Rev Drug Discov 5: 219-234, 2006.

18. Martz CA, Ottina KA, Singleton KR, Jasper JS, Wardell SE, Peraza-Penton A, Anderson GR, Winter PS, Wang T, Alley HM, et al: Systematic identification of signaling pathways with potentia to confer anticancer drug resistance. Sci Signal 7: ra121, 2014.

19. Yun M, Lee D, Park MN, Kim EO, Sohn EJ, Kwon BM and Kim SH: Cinnamaldehyde derivative (CB-PIC) sensitizes chemoresistant cancer cells to drug-induced apoptosis via suppression of MDR1 and its upstream STAT3 and AKT signalling. Cell Physiol Biochem 35: 1821-1830, 2015.

20. Qin A, Yu Q, Gao Y, Tan J, Huang H, Qiao Z and Qian W: Inhibition of STAT3/cyclinD1 pathway promotes chemotherapeutic sensitivity of colorectal caner. Biochem Biophys Res Commun 457: 681-687, 2015

21. Lin L, Sabnis AJ, Chan E, Olivas V, Cade L, Pazarentzos E, Asthana S, Neel D, Yan JJ, Lu X, et al: The Hippo effector YAP promotes resistance to RAF- and MEK-targeted cancer therapies. Nat Genet 47: 250-256, 2015

22. Yoshikawa K, Noguchi K, Nakano Y, Yamamura M, Takaoka K, Hashimoto-Tamaoki T and Kishimoto H: The Hippo pathway transcriptional co-activator, YAP, confers resistance to cisplatin in human oral squamous cell carcinoma. Int J Oncol 46 : 2364-2370, 2015.

23. Li Y, VandenBoom TG II, Kong D, Wang Z, Ali S, Philip PA and Sarkar FH: Up-regulation of miR-200 and let-7 by natural agents leads to the reversal of epithelial-to-mesenchymal transition in gemcitabine-resistant pancreatic cancer cells. Cancer Res 69: 6704-6712, 2009.

24. Giovannetti E, Funel N, Peters GJ, Del Chiaro M, Erozenci LA, Vasile E, Leon LG, Pollina LE, Groen A, Falcone A, et al: MicroRNA-21 in pancreatic cancer: Correlation with clinical outcome and pharmacologic aspects underlying its role in the modulation of gemcitabine activity. Cancer Res 70: 4528-4538, 2010.

25. Hwang JH, Voortman J, Giovannetti E, Steinberg SM, Leon LG, Kim YT, Funel N, Park JK, Kim MA, Kang GH, et al: Identification of microRNA-21 as a biomarker for chemoresistance and clinical outcome following adjuvant therapy in resectable pancreatic cancer. PLoS One 5: e10630, 2010.

26. Wang M, Ren D, Guo W, Huang S, Wang Z, Li Q, Du H, Song L and Peng X: N-cadherin promotes epithelial-mesenchymal transition and cancer stem cell-like traits via ErbB signaling in prostate cancer cells. Int J Oncol 48: 595-606, 2016.

27. Hahn WC, Dessain SK, Brooks MW, King JE, Elenbaas B, Sabatini DM, DeCaprio JA and Weinberg RA: Enumeration of the simian virus 40 early region elements necessary for human cell transformation. Mol Cell Biol 22: 2111-2123, 2002.

28. Zhang X, Ren D, Guo L, Wang L, Wu S, Lin C, Ye L, Zhu J, Li J, Song L, et al: Thymosin beta 10 is a key regulator of tumorigenesis and metastasis and a novel serum marker in breast cancer. Breast Cancer Res 19: 15, 2017.

29. Zhang X, Chen Y, Hao L, Hou A, Chen X, Li Y, Wang R, Luo P, Ruan Z, Ou J, et al: Macrophages induce resistance to 5-fluorouracil chemotherapy in colorectal cancer through the release of putrescine. Cancer Lett 381: 305-313, 2016.

30. Li X, Liu F, Lin B, Luo H, Liu M, Wu J, Li C, Li R, Zhang X, Zhou K, et al: miR-150 inhibits proliferation and tumorigenicity via retarding G1/S phase transition in nasopharyngeal carcinoma. Int J Oncol: Mar 10, 2017 (Epub ahead of print). doi: 10.3892/ijo.2017.3909.

31. Tan G, Cao X, Dai Q, Zhang B, Huang J, Xiong S, Zhang Y, Chen W, Yang J and Li H: A novel role for microRNA-129-5p in inhibiting ovarian cancer cell proliferation and survival via direct suppression of transcriptional co-activators YAP and TAZ. Oncotarget 6: 8676-8686, 2015.
32. Hall CA, Wang R, Miao J, Oliva E, Shen X, Wheeler T, Hilsenbeck SG, Orsulic S and Goode S: Hippo pathway effector Yap is an ovarian cancer oncogene. Cancer Res 70: 8517-8525, 2010.

33. Guo PD, Lu XX, Gan WJ, Li XM, He XS, Zhang S, Ji QH, Zhou F, Cao Y, Wang JR, et al: RAR $\gamma$ downregulation contributes to colorectal tumorigenesis and metastasis by derepressing the Hippo-Yap pathway. Cancer Res 76: 3813-3825, 2016.

34. Zhao B, Ye X, Yu J, Li L, Li W, Li S, Yu J, Lin JD, Wang CY, Chinnaiyan AM, et al: TEAD mediates YAP-dependent gene induction and growth control. Genes Dev 22: 1962-1971, 2008.

35. Chan SW, Lim CJ, Loo LS, Chong YF, Huang C and Hong W: TEADs mediate nuclear retention of TAZ to promote oncogenic transformation. J Biol Chem 284: 14347-14358, 2009.

36. Du C, Huang D, Peng Y, Yao Y, Zhao Y, Yang Y, Wang H, Cao L, Zhu WG and Gu J: 5-Fluorouracil targets histone acetyltransferases p300/CBP in the treatment of colorectal cancer. Cancer Lett 400: 183-193, 2017

37. Pan D: The hippo signaling pathway in development and cancer. Dev Cell 19: 491-505, 2010.

38. Halder G and Johnson RL: Hippo signaling: Growth control and beyond. Development 138: 9-22, 2011.

39. Dan I, Watanabe NM and Kusumi A: The Ste20 group kinases as regulators of MAP kinase cascades. Trends Cell Biol 11: 220-230, 2001

40. Yu FX and Guan KL: The Hippo pathway: Regulators and regulations. Genes Dev 27: 355-371, 2013.

41. Harvey KF, Zhang X and Thomas DM: The Hippo pathway and human cancer. Nat Rev Cancer 13: 246-257, 2013.

42. Liu CY, Zha ZY, Zhou X, Zhang H, Huang W, Zhao D, Li T, Chan SW, Lim CJ, Hong W, et al: The hippo tumor pathway promotes TAZ degradation by phosphorylating a phosphodegron and recruiting the SCF $\{$ beta\}-TrCP E3 ligase. J Biol Chem 285: 37159-37169, 2010.

43. Xiang L, Gilkes DM, Hu H, Takano N, Luo W, Lu H, Bullen JW, Samanta D, Liang H and Semenza GL: Hypoxia-inducible factor 1 mediates TAZ expression and nuclear localization to induce the breast cancer stem cell phenotype. Oncotarget 5: 12509-12527, 2014.

44. Mo JS, Park HW and Guan KL: The Hippo signaling pathway in stem cell biology and cancer. EMBO Rep 15: 642-656, 2014.

45. Huang J, Wu S, Barrera J, Matthews K and Pan D: The Hippo signaling pathway coordinately regulates cell proliferation and apoptosis by inactivating Yorkie, the Drosophila homolog of YAP. Cell 122: 421-434, 2005.

46. Lei QY, Zhang H, Zhao B, Zha ZY, Bai F, Pei XH, Zhao S, Xiong Y and Guan KL: TAZ promotes cell proliferation and epithelial-mesenchymal transition and is inhibited by the hippo pathway. Mol Cell Biol 28: 2426-2436, 2008.

47. Zhou Z, Hao Y, Liu N, Raptis L, Tsao MS and Yang X: TAZ is a novel oncogene in non-small cell lung cancer. Oncogene 30: 2181-2186, 2011.

48. Lee KP, Lee JH, Kim TS, Kim TH, Park HD, Byun JS, Kim MC, Jeong WI, Calvisi DF, Kim JM, et al: The Hippo-Salvador pathway restrains hepatic oval cell proliferation, liver size, and liver tumorigenesis. Proc Natl Acad Sci USA 107: 8248-8253, 2010.

49. Zhou D, Zhang Y, Wu H, Barry E, Yin Y, Lawrence E, Dawson D, Willis JE, Markowitz SD, Camargo FD, et al: Mst1 and Mst2 protein kinases restrain intestinal stem cell proliferation and colonic tumorigenesis by inhibition of Yes-associated protein (Yap) overabundance. Proc Natl Acad Sci USA 108: E1312-E1320, 2011.

50. Reddy BV and Irvine KD: Regulation of Hippo signaling by EGFR-MAPK signaling through Ajuba family proteins. Dev Cell 24: 459-471, 2013.

51. Fan R, Kim NG and Gumbiner BM: Regulation of Hippo pathway by mitogenic growth factors via phosphoinositide 3-kinase and phosphoinositide-dependent kinase-1. Proc Natl Acad Sci USA 110: 2569-2574, 2013.

52. Chen D, Sun Y, Wei Y, Zhang P, Rezaeian AH, Teruya-Feldstein J, Gupta S, Liang H, Lin HK, Hung MC, et al: LIFR is a breast cancer metastasis suppressor upstream of the Hippo-YAP pathway and a prognostic marker. Nat Med 18: 1511-1517, 2012.

53. Zhang Y and Lai ZC: Mob as tumor suppressor is regulated by bantam microRNA through a feedback loop for tissue growth control. Biochem Biophys Res Commun 439: 438-442, 2013.

54. Lin CW, Chang YL, Chang YC, Lin JC, Chen CC, Pan SH, Wu CT, Chen HY, Yang SC, Hong TM, et al: MicroRNA-135b promotes lung cancer metastasis by regulating multiple targets in the Hippo pathway and LZTS1. Nat Commun 4: 1877, 2013. 
55. Chen M, Wang M, Xu S, Guo X and Jiang J: Upregulation of miR-181c contributes to chemoresistance in pancreatic cancer by inactivating the Hippo signaling pathway. Oncotarget 6 : 44466-44479, 2015.

56. Allen KE and Weiss GJ: Resistance may not be futile: MicroRNA biomarkers for chemoresistance and potential therapeutics. Mol Cancer Ther 9: 3126-3136, 2010.

57. Gisel A, Valvano M, El Idrissi IG, Nardulli P, Azzariti A, Carrieri A, Contino $M$ and Colabufo NA: miRNAs for the detection of multidrug resistance: Overview and perspectives. Molecules 19: 5611-5623, 2014.

58. Yin Y, Zhang B, Wang W, Fei B, Quan C, Zhang J, Song M, Bian Z, Wang Q, Ni S, et al: miR-204-5p inhibits proliferation and invasion and enhances chemotherapeutic sensitivity of colorectal cancer cells by downregulating RAB22A. Clin Cancer Res 20: 6187-6199, 2014.

59. Fang L, Li H, Wang L, Hu J, Jin T, Wang J and Yang BB: MicroRNA-17-5p promotes chemotherapeutic drug resistance and tumour metastasis of colorectal cancer by repressing PTEN expression. Oncotarget 5: 2974-2987, 2014.

60. Zhao Y and Yang X: The Hippo pathway in chemotherapeutic drug resistance. Int J Cancer 137: 2767-2773, 2015.

61. Fujimoto D, Ueda Y, Hirono Y, Goi T and Yamaguchi A: PAR1 participates in the ability of multidrug resistance and tumorigenesis by controlling Hippo-YAP pathway. Oncotarget 6: 34788-34799, 2015.

62. Su Z, Zhi X, Zhang Q, Yang L, Xu H and Xu Z: LncRNA H19 functions as a competing endogenous RNA to regulate AQP3 expression by sponging $\mathrm{miR}-874$ in the intestinal barrier. FEBS Lett 590: 1354-1364, 2016.

63. Kushwaha P, Khedgikar V, Sharma D, Yuen T, Gautam J, Ahmad N, Karvande A, Mishra PR, Trivedi PK, Sun L, et al: MicroRNA 874-3p exerts skeletal anabolic effects epigenetically during weaning by suppressing Hdacl expression. J Biol Chem 291: 3959-3966, 2016.

64. Wu G, Yang G, Zhang R, Xu G, Zhang L, Wen W, Lu J, Liu J and Yu Y: Altered microRNA expression profiles of extracellular vesicles in nasal mucus from patients with allergic rhinitis. Allergy Asthma Immunol Res 7: 449-457, 2015.

65. Colangelo V, François S, Soldà G, Picco R, Roma F, Ginelli E and Meneveri R: Next-generation sequencing analysis of miRNA expression in control and FSHD myogenesis. PLoS One 9: e108411, 2014

66. Suojalehto H, Lindström I, Majuri ML, Mitts C, Karjalainen J Wolff $\mathrm{H}$ and Alenius $\mathrm{H}$ : Altered microRNA expression of nasal mucosa in long-term asthma and allergic rhinitis. Int Arch Allergy Immunol 163: 168-178, 2014.

67. Sheinerman KS, Tsivinsky VG, Abdullah L, Crawford F and Umansky SR: Plasma microRNA biomarkers for detection of mild cognitive impairment: Biomarker validation study. Aging 5: 925-938, 2013.
68. Sheinerman KS, Tsivinsky VG, Crawford F, Mullan MJ, Abdullah L and Umansky SR: Plasma microRNA biomarkers for detection of mild cognitive impairment. Aging 4: 590-605, 2012.

69. Zhang LQ, Sun SL, Li WY, Feng Z, Xu XY, Zhuang QS and Fang J: Decreased expression of tumor suppressive miR-874 and its clinical significance in human osteosarcoma. Genet Mol Res 14: 18315-18324, 2015.

70. Dong D, Gong Y, Zhang D, Bao H and Gu G: miR-874 suppresses the proliferation and metastasis of osteosarcoma by targeting E2F3. Tumour Biol 37: 6447-6455, 2016.

71. Fisher JN, Terao M, Fratelli M, Kurosaki M, Paroni G, Zanetti A, Gianni M, Bolis M, Lupi M, Tsykin A, et al: MicroRNA networks regulated by all-trans retinoic acid and Lapatinib control the growth, survival and motility of breast cancer cells. Oncotarget 6: 13176-13200, 2015

72. Zhang X, Tang J, Zhi X, Xie K, Wang W, Li Z, Zhu Y, Yang L, $\mathrm{Xu} \mathrm{H}$ and $\mathrm{Xu} \mathrm{Z}$ : miR-874 functions as a tumor suppressor by inhibiting angiogenesis through STAT3/VEGF-A pathway in gastric cancer. Oncotarget 6: 1605-1617, 2015.

73. Wang L, Gao W, Hu F, Xu Z and Wang F: MicroRNA-874 inhibits cell proliferation and induces apoptosis in human breast cancer by targeting CDK9. FEBS Lett 588: 4527-4535, 2014.

74. Jiang B, Li Z, Zhang W, Wang H, Zhi X, Feng J, Chen Z, Zhu Y, Yang L, Xu H, et al: miR-874 inhibits cell proliferation, migration and invasion through targeting aquaporin-3 in gastric cancer. J Gastroenterol 49: 1011-1025, 2014

75. Kesanakurti D, Maddirela DR, Chittivelu S, Rao JS and Chetty C: Suppression of tumor cell invasiveness and in vivo tumor growth by microRNA-874 in non-small cell lung cancer. Biochem Biophys Res Commun 434: 627-633, 2013.

76. Nohata N, Hanazawa T, Kinoshita T, Inamine A, Kikkawa N, Itesako T, Yoshino H, Enokida H, Nakagawa M, Okamoto Y, et al: Tumour-suppressive microRNA-874 contributes to cell proliferation through targeting of histone deacetylase 1 in head and neck squamous cell carcinoma. Br J Cancer 108: 1648-1658, 2013.

77. Han J, Liu Z, Wang N and Pan W: MicroRNA-874 inhibits growth, induces apoptosis and reverses chemoresistance in colorectal cancer by targeting X-linked inhibitor of apoptosis protein. Oncol Rep 36: 542-550, 2016.

78. Wang XJ, Xia M and Bi WP: Decreased expression of miR-874 and its tumor suppressive function in human colorectal cancer. Genet Mol Res 15: 15028077, 2016.

79. Zhao B and Dong AS: MiR-874 inhibits cell growth and induces apoptosis by targeting STAT3 in human colorectal cancer cells. Eur Rev Med Pharmacol Sci 20: 269-277, 2016. 